\title{
Impactos Socioeconômicos de Reduções nas Perdas Pós-colheita de Produtos Agrícolas no Brasil ${ }^{1}$
}

\author{
Cinthia Cabral da Costa², Joaquim José Martins Guilhoto ${ }^{3}$ e \\ Heloisa Lee Burnquist ${ }^{4}$
}

Resumo: Países da América Latina, incluindo o Brasil, apresentam níveis de perdas pós-colheita de produtos agrícolas superiores aos observados em países mais desenvolvidos. O presente estudo teve como objetivo estimar os impactos que a economia brasileira poderia obter caso os níveis destas perdas no País fossem reduzidas para os níveis observados em países de alta renda. Para isto, calculou-se a redução nas perdas pós-colheita de produtos agrícolas no País e, utilizando a matriz insumo-produto do Brasil, foram estimados os impactos que esta redução poderia causar na economia brasileira, resultante do aumento dos serviços de processamento, transporte e comércio, que seriam incluídos naqueles produtos recuperados. Observou-se que, a preços de 2012, esta redução nas perdas pós-colheita implicaria em aumento de R \$ 9,8 bilhões no valor da produção agrícola. Considerando os impactos diretos, indiretos e de efeito renda, identificou-se que um aumento na demanda por serviços de processamento, transporte e comércio originado pelo aumento desta oferta, pode elevar o valor da produção da economia em R $\$ 18$ bilhões, o PIB do País em R\$ 9,7 bilhões e gerar mais de 300 mil empregos. Tais resultados ilustram que, face à grande importância dos produtos agrícolas para a economia brasileira, a redução nas perdas pós-colheita pode gerar benefícios econômicos substanciais para o País.

Palavras-chaves: Análise de insumo-produto; Perda pós-colheita; Transporte; Comércio; Processamento.

Abstract: In the countries of Latin America, including Brazil, the levels of losses in the post-harvest stages of agricultural products is higher than that observed for more developed

1. Data de submissão: 18 de junho de 2014. Data de aceite: 17 de junho de 2015.

2. Empresa Brasileira de Pesquisa Agropecuária - Embrapa. São Carlos, SP, Brasil. E-mail: cinthia.cabral.da.costa@gmail.com

3. Faculdade de Economia, Administração e Contabilidade da Universidade de São Paulo (FEA/USP). São Paulo, SP, Brasil. E-mail: guilhoto@usp.br

4. Escola Superior de Agribultura Luiz de Queiroz. Universidade de São Paulo - ESALQ/USP. Piracicaba, SP, Brasil. E-mail: hlburnqu@usp.br 
countries. The present study estimated the impacts of reduction in post-harvest losses of agricultural products to levels observed in countries of high income. We calculated this reduction and, using the input-output matrix of Brazil, estimated the impacts that this drop in losses could have on the Brazilian economy. These impacts are due to the increase in the following services: processing, transportation and trade, which would be included in those products recovered. The reduction in post-harvest losses would imply an increase of $R \$ 9.8$ billion in the value of agricultural production (in 2012 values). In addition, it can be seen that the direct, indirect and income effects of an increase in demand for services (processing, transport and trade) caused by the increase of supply, can raise the value of output of the economy in $R \$ 18$ billion, the country's GDP in $R \$ 9.7$ billion and generate more than 300,000 jobs. These results illustrate that, in view of the great importance of agricultural products for the Brazilian economy, the reduction in losses after harvest can generate substantial economic benefits for the country.

Key-words: Input-output analysis; Post-harvest losses; Transportation and trade; Processing.

DOI http://dx.doi.org/10.1590/1234-56781806-9479005303002

Classificação JEL: Q18, R15, O18.

\section{Introdução}

Apesar de ser reconhecidamente importante, o valor das perdas pós-colheita de produtos agrícolas é de difícil mensuração a partir dos dados econômicos mundiais. Estudo conduzido pela FAO (GUSTAVSSON et al., 2011) buscou suprir esta deficiência, fornecendo estimativas para grupos de países definidos com base nas similaridades geoeconômicas, referentes às perdas de alimentos em diferentes etapas da cadeia produtiva. O levantamento realizado naquele estudo permite a realização de várias análises e estudos mais aprofundados sobre este tema. Gustavsson et al. (2011) constataram que as perdas pós-colheita - objeto do presente estudo - para os países com baixo/médio nível de renda, são relativamente superiores àquelas observadas para os países de alta renda. Esta comparação das perdas entre diferentes grupos de países, para diferentes grupos de produtos e estágios do processo de pós-colheita, resulta em um bom diagnóstico dos pontos que permitiriam um avanço na redução das perdas, principalmente para países com grande produção agrícola e cuja economia é altamente impactada por estes produtos, como é o caso do Brasil.

Conforme apontado no estudo da FAO, a maior importância das informações sobre as perdas e desperdício de alimentos é a conscien- tização da população quanto à possibilidade de redução da fome no mundo. Neste aspecto, tanto as perdas pós-colheita quanto os desperdícios, que são os alimentos adquiridos pelo consumidor final, mas não consumidos, são importantes para a melhor distribuição dos alimentos entre a população. Contudo, impactos econômicos relevantes também podem ser obtidos pela redução, especificamente, de parcela destas perdas. Neste sentido, dado o volume de produtos cujas perdas possam ser reduzidas, pode-se aumentar as receitas com exportação e aumentar a demanda por serviços de comércio, transporte e de beneficiamento para estes mesmos produtos.

O presente estudo teve como objetivo identificar onde ocorrem as maiores perdas pós-colheita de produtos agrícolas para o caso brasileiro e estimar os impactos econômicos da redução de tais perdas para os níveis observados em países de alta renda. Os impactos econômicos foram estimados considerando o mercado de bens e serviços de toda a economia brasileira. Assim, este estudo buscou responder as seguintes questões sobre as perdas pós-colheita: (i) em que etapas da cadeia produtiva as perdas pós-colheita no País são mais problemáticas? (ii) Em quanto podemos reduzir as perdas pós-colheita no Brasil se compararmos às estatísticas para os países mais ricos? (iii) Quais os choques sobre o mercado de bens e serviços da economia resultantes da redução 
nestas perdas? (iv) Quais os impactos econômicos para toda a economia do País derivados destes choques?

Para responder a estas questões, na próxima seção (seção 2) é descrita uma análise dos resultados obtidos pela $\mathrm{FAO}$, principalmente para a região da América Latina e uma análise comparativa das perdas nesta região, onde situa-se o Brasil, com aquelas estimadas para países de alta renda. Na seção 2 os itens (i) e (ii) são respondidos. A seguir (seção 3), o método utilizado para obter as estimativas de possíveis reduções nas perdas pós-colheita para o mercado brasileiro é descrito, assim como a análise dos impactos das mesmas, que representa as respostas aos itens (iii) e (iv). A seção 4 apresenta os resultados obtidos, e a seção 5 descreve a conclusão deste estudo.

\section{Análise das perdas e desperdício de alimentos no mundo e o potencial de redução nos países da América Latina}

\section{No estudo realizado pela FAO (GUSTAVSSON} et al., 2011), utilizado como base para as análises realizadas neste artigo, a mensuração das perdas e desperdício de alimentos no mundo foi mensurada como uma medida importante para os esforços de combate à fome, aumento de renda e melhoria na segurança alimentar nos países mais pobres do mundo. Neste sentido, aquele estudo considerou apenas os produtos agrícolas destinados à alimentação humana.

Apesar de utilizar as informações coletadas naquele estudo, a presente análise engloba não apenas os produtos destinados à alimentação humana, mas toda a produção agrícola do País ${ }^{5}$. No item 3.1 é descrito o método utilizado para isto. Uma outra consideração importante em relação aos resultados apresentados por Gustavsson

5. Como produtos agrícolas foi considerada a definição do Ministério da Agricultura, Pecuária e Abastecimento (Mapa), que inclui peixes e frutos do mar. Estes produtos não são definidos como agrícolas pela Organização Mundial do Comércio (OMC). et al. (2011) é que não apenas as perdas de alimentos durante o processo produtivo foram mensuradas, mas também os desperdícios dos mesmos pelos consumidores finais. Esta parte das perdas, definida como desperdício, não foi considerada na análise realizada neste artigo uma vez que os serviços de toda cadeia produtiva já foram incorporados no produto final que foi desperdiçado. Desta maneira, apesar de não consumidos, estes produtos geraram renda em toda cadeia produtiva e, portanto, assume-se que sua redução não representa impactos positivos sobre o mercado de bens e serviços da economia.

Já as perdas estimadas em diferentes etapas da cadeia são de extrema importância para a análise dos impactos econômicos no mercado de bens e serviços, uma vez que, em cada etapa, diferentes bens e serviços deixam de ser incorporados ao produto até que este chegue ao consumidor final. As etapas descritas no estudo da FAO são: produção agrícola; manuseio pós-colheita e armazenamento; processamento e acondicionamento; distribuição, e a última etapa, indicada pelo consumo, representa as estimativas de desperdício. E o conjunto de produtos agrícolas analisado foi: cereais, raízes e tubérculos, oleaginosas e leguminosas, frutas e hortaliças, carnes, peixes e frutos do mar, leite e ovos.

A grande contribuição do estudo da FAO (GUSTAVSSON et al., 2011) está associada à atribuição de valores, ou seja, uma mensuração das perdas. Embora tais valores não sejam descritos individualmente para os países, os resultados em termos percentuais para a região onde os países estão localizados podem ser utilizados como parâmetros para análise dos impactos para os mesmos. Assim, foram utilizados os levantamentos descritos para a América Latina como parâmetro para estimar as perdas no Brasil neste estudo.

Pela natureza de perecibilidade dos produtos, é pequena a possibilidade de anular totalmente as perdas de alimentos. Assim, um padrão que pode ser adotado para se obter níveis aceitáveis destas perdas são os menores níveis observados no mundo. Desta maneira, para analisar as perdas pós-colheita da América Latina, essas 
Tabela 1. Percentuais de perdas verificadas na América Latina subtraídos dos percentuais das perdas em países de alta renda, para grupos de produtos (nas linhas) e etapas do processo de produção (nas colunas)

\begin{tabular}{lccccc}
\hline & $\begin{array}{c}\text { Produção } \\
\text { Agrícola }\end{array}$ & $\begin{array}{c}\text { Manuseio pós-colheita } \\
\text { e armazenamento }\end{array}$ & $\begin{array}{c}\text { Processamento e } \\
\text { acondicionamento }\end{array}$ & Distribuição & Consumo \\
\hline Cereais & $4,0 \%$ & $0,0 \%$ & $1,5 \%$ & $2,0 \%$ & $-15,0 \%$ \\
Raízes e tubérculos & $-6,0 \%$ & $5,0 \%$ & $-3,0 \%$ & $-4,0 \%$ & $-23,0 \%$ \\
Oleaginosas/ leguminosas & $-4,0 \%$ & $2,0 \%$ & $3,0 \%$ & $1,0 \%$ & $-2,0 \%$ \\
Frutas e hortaliças & $0,0 \%$ & $5,0 \%$ & $18,0 \%$ & $2,0 \%$ & $-23,0 \%$ \\
Carne & $2,4 \%$ & $0,4 \%$ & $0,0 \%$ & $1,0 \%$ & $-5,0 \%$ \\
Peixes e frutos do mar & $-3,7 \%$ & $4,5 \%$ & $3,0 \%$ & $1,0 \%$ & $-15,0 \%$ \\
Leite & $0,0 \%$ & $5,5 \%$ & $0,8 \%$ & $7,5 \%$ & $-3,0 \%$ \\
Ovos & $2,0 \%$ & $0,0 \%$ & $0,0 \%$ & $2,0 \%$ & $-4,0 \%$ \\
\hline
\end{tabular}

Fonte: Elaborado pelos autores a partir de Gustavsson et al. (2011).

são comparadas com as observadas nos países de alta renda. Estes grupos de países apresentaram resultados muito semelhantes. A Tabela 1 mostra o quanto, em pontos percentuais, as perdas observadas para os países da América Latina são superiores àquelas observadas para os grupos de países de alta renda (Europa, América do Norte e Oceania).

Os percentuais positivos observados para os grupos de produtos desagregados têm suas células sombreadas na Tabela 1. Verifica-se, neste caso, que as perdas de alimentos na América Latina, em comparação com os países de alta renda, são maiores nas seguintes etapas: manuseio pós-colheita e armazenamento; processamento e acondicionamento e distribuição. Isto ocorre pela deficiência em infraestrutura nos países latino-americanos, o que prejudica o armazenamento, transporte e comércio destes produtos. Principalmente para aqueles produtos que precisam de locais refrigerados para conservação pós-colheita, exceto carnes em que a refrigeração é essencial, a questão da infraestrutura é fundamental e sua deficiência é a causa de grandes perdas para frutas e hortaliças.

Os valores dos percentuais de perdas dos países da América Latina superiores aos observados para os países de alta renda - indicados nas células sombreadas da Tabela 1 - podem ser utilizados como parâmetros para se alcançar reduções nas perdas observadas, particularmente neste estudo, que enfoca o caso brasileiro. Ou seja, estes percentuais, em cada grupo de produtos e etapas do processo pós-colheita, representam as respostas para os itens (i) e (ii) descritos na seção anterior, em que se busca responder quais etapas da pós-colheita apresentam perdas mais expressivas e quanto podemos reduzi-las considerando países mais ricos. Verifica-se que as maiores diferenças nos percentuais de perdas entre os grupos de países mais ricos e aqueles da América Latina ocorrem na etapa de processamento e acondicionamento de frutas e hortaliças $(18 \%)$. Estes percentuais são também superiores para as etapas de manuseio pós-colheita e armazenamento e distribuição. Enquanto para raízes e tubérculos são observadas perdas maiores nos países latino-americanos apenas nas etapas de manuseio pós-colheita e armazenamento, para cereais, estas perdas são superiores às dos países mais ricos apenas nas etapas de processamento e acondicionamento e na distribuição ${ }^{6}$. Chama atenção também o elevado percentual de perdas, em relação aos países mais ricos, na etapa de distribuição de leite (7,5\% maior). Já as diferenças entre as perdas no processo de produção, assim como entre os percentuais de desperdício são, na sua maioria, negativos. Ou seja, as perdas e desperdício nestas etapas são menores nos países da América

6. Para cereais, as perdas na etapa de produção agrícola também foram superiores na América Latina em relação aos países mais ricos. Entretanto, o foco do presente estudo foi na redução das perdas desde a pós-colheita até chegar ao consumidor final. 
Latina do que nos países mais ricos, e por isto não foram analisadas reduções nas perdas e desperdício nestas etapas para o Brasil.

A comparação das perdas entre diferentes grupos de países é um bom diagnóstico dos pontos em que se pode avançar mais na redução das perdas de modo geral. Por este motivo, este estudo procurou identificar os impactos no mercado de bens e serviços de toda economia brasileira derivados de tais reduções. O próximo item descreve o método e dados utilizados e, a seguir, os resultados são apresentados, discutidos e concluídos.

\section{Método e dados utilizados}

Nesta seção são descritas as duas etapas que foram utilizadas para obtenção dos resultados neste estudo. Inicialmente descreve-se como foram estimados os valores de redução nas perdas pós-colheita de produtos agrícolas no Brasil considerados neste estudo. A seguir, apresenta-se o método utilizado para estimar os impactos econômicos da redução das perdas estimadas inicialmente para toda economia brasileira. As fontes dos dados utilizados também foram descritas para cada etapa do trabalho.

\subsection{Estimativa do valor da redução das perdas no Brasil}

Para estimar os volumes da redução das perdas pós-colheita de produtos agrícolas no Brasil, foi adotado como padrão aceitável os percentuais observados destas perdas nos países de alta renda. Assim, os valores positivos dos percentuais descritos na Tabela 1 foram multiplicados pelo volume de cada grupo de produtos agrícolas disponíveis em cada etapa do processo produtivo calculados para o Brasil. As setas apresentadas na Figura 1 descrevem o caminho pelo qual o produto agrícola percorre entre o produtor e o consumidor final (as etapas são descritas nas caixas entre as setas) e onde ocorre a redução das perdas estimadas neste estudo. As perdas são descritas como A1, A2 e A3, respectivamente, para

Figura 1. Processo de serviços demandados na economia entre o processo de produção agrícola e o consumidor final e indicação das etapas em que foram estimadas as reduções de perdas neste artigo

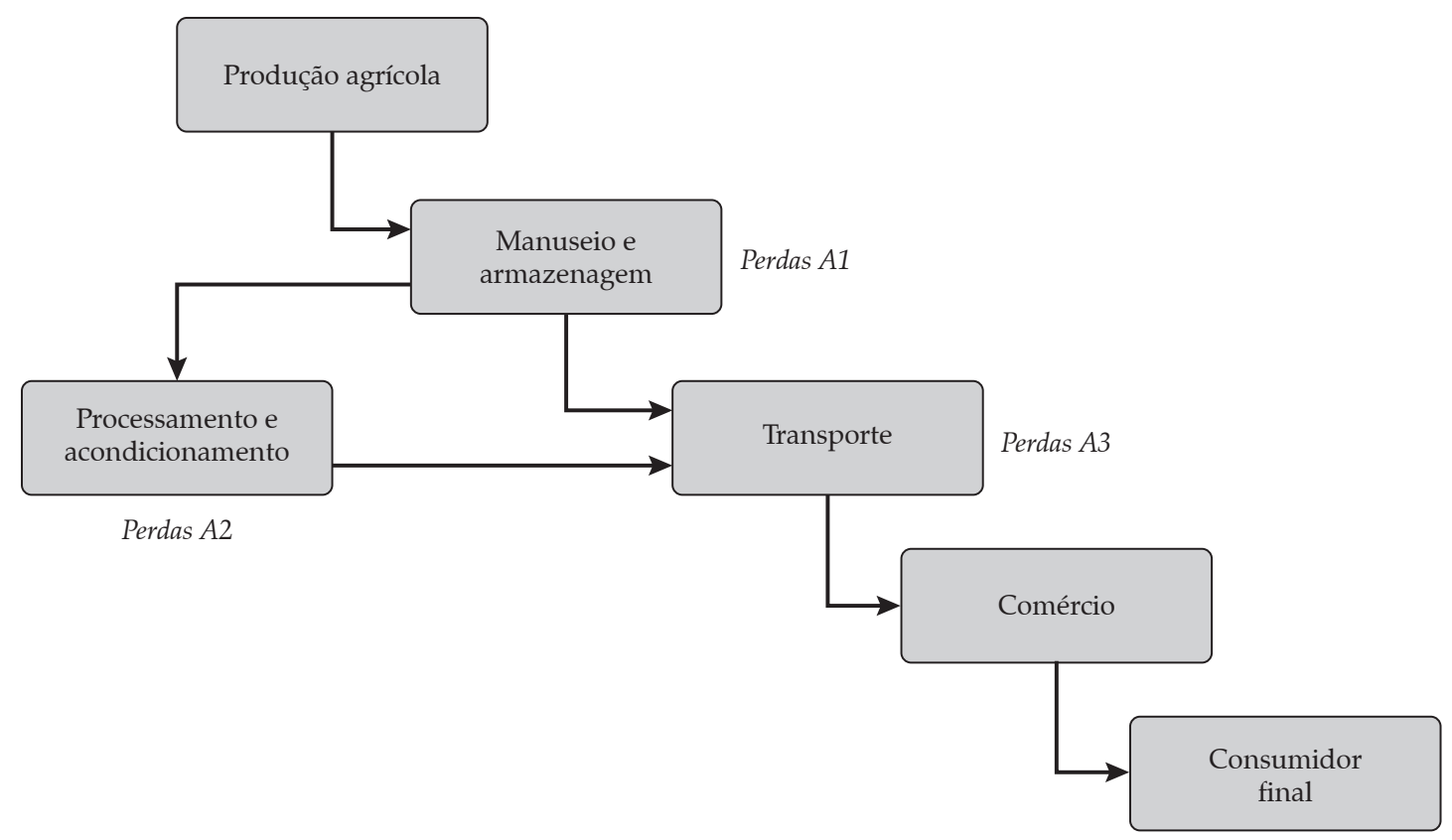


manuseio pós-colheita e armazenamento; processamento e acondicionamento, e distribuição.

Segundo Gustavsson et al. (2013), para as duas primeiras etapas do processo, produção agrícola e manuseio pós-colheita e armazenamento, o volume disponível é o volume produzido pelo país. Assim, os volumes disponíveis na etapa de manuseio e armazenagem, utilizados para estimar a redução nas perdas A1, para cada um dos grupos de produtos agrícolas, foram obtidos na Produção Agrícola Municipal (PAM), divulgada pelo Instituto Brasileiro de Geografia e Estatística (IBGE, 2014b) 7 . Uma vez que os dados mundiais utilizados no levantamento da FAO (GUSTAVSSON et al., 2011, 2013) referem-se a 2007, este mesmo ano foi utilizado para a obtenção dos volumes de produção no Brasil.

Para estimar as perdas em A2, ou seja, na etapa de "processamento e acondicionamento", apenas uma parcela do volume disponível na etapa de "manuseio pós-colheita e armazenamento" é considerada, pois outra parte do produto bruto segue para transporte sem a necessidade de passar pela etapa de processamento. Da mesma maneira, apenas uma parte do volume do "processamento e acondicionamento" é disponibilizada para a etapa de "distribuição", utilizada para estimar as perdas em A3. Para cada grupo de produtos, a Tabela 1 mostra o quanto, em pontos percentuais, as perdas na América Latina são superiores às perdas dos países de alta renda. Estes percentuais foram utilizados sobre os volumes de produção do Brasil para compor o volume disponível dos produtos em cada etapa que poderiam deixar de ser perdidos.

Entretanto, diferente do realizado no estudo da FAO, em que apenas os produtos agrícolas utilizados como alimento humano foram considerados, a redução nas perdas estimadas para o Brasil considera toda a produção agrícola, seja para alimentação humana, animal ou outra finalidade. Para isto, o coeficiente utilizado pela FAO, que

7. Exceto para carnes e ovos, cujos dados de produção, em toneladas, foram extraídos da FAO (2014a), e para peixes e frutos do mar, obtidos em FAO (2014b). foi multiplicado pela produção agrícola total ${ }^{8}$, não foi utilizado neste artigo. Todavia, da mesma maneira que foi realizado por aquele estudo, as quantidades das perdas em todas as etapas da cadeia foram calculadas em quantidades equivalentes do produto bruto.

Desta maneira, obtêm-se os volumes da redução nas perdas pós-colheita de produtos agrícolas no Brasil para níveis semelhantes aos de países mais ricos. Para transformar os volumes da redução nas perdas pós-colheita de produtos agrícolas no Brasil em valores monetários, foram calculados os preços básicos (pagos aos produtores) para cada grupo de produtos. Estes preços foram obtidos a partir das informações de volumes e valores destes produtos levantados na PAM (IBGE, 2014b) $)^{9}$. De maneira a utilizar os resultados desta etapa para a etapa seguinte, descrita na seção 3.2, foi utilizado o preço referente a $2009^{10}$.

\subsection{Estimativa dos impactos na economia brasileira}

Para estimar os impactos da redução nas perdas calculadas conforme descrito anteriormente, inicialmente foi necessário analisar os serviços ainda não incluídos sobre a produção em cada etapa do processo. A Figura 1 descreve estes serviços na ordem como ocorrem. Assim, as perdas

8. Este coeficiente é definido como "converstion and allocation factors".

9. Exceções: para as carnes, uma vez que não havia dados disponíveis no IBGE, foram utilizados os dados da FAO (2014a). Para ovos, os dados da PPM (IBGE, 2014c) existem apenas para volume em dúzias e valor da produção. Assim, o preço em toneladas deste produto foi obtido dividindo o valor produzido descrito na PPM (IBGE, 2014c) pelo volume em toneladas divulgado pela FAO (2014a). Para peixes e frutos do mar, o volume em toneladas foi obtido pela FAO (2014b) e o valor foi obtido na tabela de usos de bens e serviços das Contas Nacionais para o produto "pesca e aquicultura" (IBGE, 2014a).

10. Com o propósito de compatibilizar os dados do estudo da FAO, que se referem a 2007, e com os dados utilizados para estimar os impactos na economia brasileira, que são da matriz insumo produto (MIP) de 2009, os valores foram estimados com base no volume de 2007 e nos preços de 2009. O uso dos preços no mesmo ano da MIP é essencial para estimar os valores dos choques. Já os volumes de produtos agrícolas produzidos em 2007 são muito parecidos com aqueles observados em 2009 (FAO, 2014a, 2014b). 
na etapa de manuseio e armazenamento, identificadas como "A1", deixam de receber os seguintes serviços: processamento, na proporção que este produto é processado na economia (a) $)^{11}$; transporte e comercialização. Já as perdas na etapa de processamento e acondicionamento, definidas como "A2", deixam de receber os serviços de transporte e comércio na economia. Para as perdas na etapa de transporte, chamadas de "A3", apenas os serviços de comércio antes de atingir o consumidor final não são mais recebidos. Nesta seção é descrito o método utilizado para estimar o valor das perdas nestes serviços não incluídos e os impactos de efeito direto, indireto e renda derivados destas perdas na economia.

A estimativa do valor dos serviços a serem demandados na economia ao reduzir as perdas foi estimado considerando-se a proporção que cada produto é processado na economia (a) e as margens de transporte (Mt) e de comércio $(\mathrm{Mc})$ tanto para os produtos sem processamento, definidos como produtos brutos $\left(\mathrm{Mt}_{\mathrm{b}}\right.$ e $\mathrm{Mc}_{\mathrm{b}}$ ), quanto para os produtos agrícolas processados $\left(\mathrm{Mt}_{\mathrm{p}} \mathrm{e}\right.$ $\mathrm{Mc}_{\mathrm{p}}$ ). Estes parâmetros foram definidos considerando-se as seguintes informações obtidas das tabelas das Contas Nacionais do Brasil de 2009 (IBGE, 2014a): (i) os valores dos produtos brutos vendidos para o setor de processamento (este último representado pelo setor "alimentos e bebidas"), na tabela de uso de bens e serviços; (ii) os valores das margens de transporte e comércio dos produtos brutos e seus respectivos processados na tabela de recursos de bens e serviços. Estes valores foram transformados em percentuais do valor da produção a preços básicos. A Tabela 1A do Anexo descreve estes percentuais para os produtos brutos e processados analisados.

Para obter os choques a serem inseridos na MIP, foi necessário também conhecer o quanto o produto bruto aumenta seu valor ao ser processado. O percentual de quanto o valor do produto processado considerado corresponde ao valor do

11. O produto agrícola processado corresponde à parcela da produção agrícola que é destinada ao consumo intermediário de outras atividades produtivas, no caso, do setor de alimentos e bebidas. produto bruto utilizado no processamento (b) é também descrito na Tabela 1A, e foi calculado dividindo o valor da produção dos produtos processados selecionados pelo valor dos produtos brutos vendidos para o setor de processamento. Tais valores também foram obtidos na tabela de uso de bens e serviços das Contas Nacionais do Brasil de 2009 (IBGE, 2014a). O valor percentual do aumento no valor ao processar (b) também foi multiplicado pelo valor do produto bruto para calcular as margens de comércio e transporte do produto processado, uma vez que estas margens foram calculadas sobre o valor do processado e não do produto bruto.

As equações de (1) a (3) a seguir descrevem como foram estimados os valores dos choques nos setores de alimentos processados, transporte e comércio, respectivamente:

Setor de alimentos processados:

$\mathrm{A} 1 * \mathrm{a} * \mathrm{~b}$

Setor de transporte:

$A 1^{*}(1-a) * M t_{b}+A 1 * a * b * M t_{p}+A 2 * M t_{b}$

Setor de comércio:

$\mathrm{A} 1 *(1-\mathrm{a}) * \mathrm{Mc}_{\mathrm{b}}+$

$+\mathrm{A1}^{*} \mathrm{a} * \mathrm{~b} * \mathrm{Mc}_{\mathrm{p}}+(\mathrm{A} 2+\mathrm{A} 3) * \mathrm{Mc}_{\mathrm{b}}$

Os valores dos serviços demandados (processamento, transporte e comércio) foram aplicados como choques de aumento de demanda nos setores correspondentes a cada um deles na matriz de insumo-produto (MIP) da economia brasileira. Para isto foi utilizada a estimativa da MIP mais recente para o País - 2009 - obtida a partir das mesmas tabelas das Contas Nacionais utilizadas para obter os coeficientes descritos na Tabela 1A (IBGE, 2014a), segundo método descrito por Guilhoto e Sesso (2005).

De acordo com Miller \& Blair (2009), os impactos sobre o valor da produção da economia decorrentes dos choques de demanda descritos anteriormente são obtidos conforme descrito na equação (4):

$$
\mathrm{X}=(\mathrm{I}-\mathrm{A})^{-1} * \mathrm{Y}
$$


Em que "A" é a matriz de coeficientes técnicos diretos; " $X$ " é a matriz de valor bruto da produção; "Y" é a matriz de demanda final, em que foram inseridos os choques e $(\mathrm{I}-\mathrm{A})^{-1}$ é a matriz de coeficientes técnicos de insumo diretos e indiretos, conhecida como a matriz inversa de Leontief.

É a partir da matriz inversa de Leontief que são obtidos os chamados multiplicadores de produção de um choque de demanda final (choque na variável Y) na economia. Tais multiplicadores (também chamados de impactos do choque) são os efeitos diretos do choque proposto, assim como os indiretos (a montante da cadeia produtiva).

Uma vez que os impactos de um choque contabilizam toda a produção a montante da etapa de produção em que o choque foi realizado, deve-se proceder um ajustamento de maneira que estes impactos reflitam apenas os serviços incluídos para a etapa de processamento e não contenham, também, os serviços da produção agrícola utilizada como insumo deste processo. Retirar a produção agrícola deste impacto é importante pois este processamento ocorreria com produtos já produzidos, mas que tiveram suas perdas pós-colheita reduzidas. Assim, além dos choques descritos nestas equações, foi ainda inserido um choque adicional nos setores dos produtos brutos, mas de valor negativo. Desta maneira, o impacto do processamento na economia foi estimado somando os impactos do aumento na demanda do processado e da redução correspondente na produção dos produtos brutos.

Além dos impactos diretos e indiretos, pode-se também obter os impactos de efeito renda, que correspondem ao aumento de demanda das famílias resultante dos impactos diretos e indiretos. Para obter este efeito adicional na economia, a matriz inversa de Leontief é obtida a partir de uma matriz $\bar{A}$ de coeficientes técnicos, em que se considera a endogeneização no consumo das famílias, de modo que o multiplicador setorial é definido a partir da matriz $(I-\bar{A})^{-1}$.

A partir do impacto no valor da produção foram também calculados os impactos na economia sobre o número de empregos $\left(Z_{\mathrm{E}}\right)$; valor das remunerações do trabalho $\left(Z_{R}\right)$; valor das impor- tações $\left(Z_{\mathrm{M}}\right)$ e produto interno bruto - PIB $\left(\mathrm{Z}_{\mathrm{PIB}}\right)$. Para isto, os impactos na produção estimados na equação (4) foram multiplicados pelos coeficientes das variáveis: emprego $\left(\mathrm{C}_{\mathrm{E}}\right)$, remunerações do trabalho $\left(\mathrm{C}_{\mathrm{R}}\right)$; importação $\left(\mathrm{C}_{\mathrm{M}}\right)$ e $\mathrm{PIB}\left(\mathrm{C}_{\mathrm{PIB}}\right)$. Todos estes coeficientes foram obtidos também de dados identificados na matriz de insumo-produto estimada. O coeficiente de cada uma destas variáveis (emprego, remuneração, importação e PIB) é obtido dividindo, para cada setor da MIP, o valor de cada uma destas informações pelo seu respectivo valor da produção.

Uma limitação do método descrito até então é que a matriz insumo-produto representa a tecnologia utilizada no País, e supomos reduzir os níveis de perdas pós-colheita sem alterar a matriz tecnológica. A mudança que a redução das perdas pode acarretar na matriz tecnológica é a redução no uso de insumos, uma vez que se tem maior eficiência nos processos pós-colheita. De maneira a minimizar esta limitação, foi reduzido o coeficiente de produção para aqueles setores que tiveram suas perdas reduzidas ${ }^{12}$. Isto porque, uma vez que as perdas são diminuídas, pode-se utilizar mais destes produtos sem ter que produzi-los novamente. Ou seja, foi calculado um novo valor dos coeficientes da matriz $\mathrm{A}_{\mathrm{i}, \mathrm{i}}$ para os setores ( $i$ ) cujas perdas foram reduzidas. Para isto considerou-se o percentual da redução nas perdas equivalentes para o produto bruto nas três etapas do processo de produção que foram consideradas neste estudo. Uma vez que o setor de produção agrícola está agregado na matriz de insumo-produto, a soma ponderada destes percentuais foi utilizada para subtrair os coeficientes $\mathrm{A}_{\mathrm{i}, \mathrm{i}}$ nos setores: agricultura, silvicultura, exploração florestal; pecuária e pesca, e alimentos e bebidas. A seguir, uma nova matriz $(\mathrm{I}-\overline{\mathrm{A}})^{-1}$ foi estimada.

12. A tecnologia utilizada pelos países mais desenvolvidos não necessariamente se aplicaria à nova tecnologia para o Brasil, pois há várias diferenças (geográficas, econômicas, climáticas etc.) que influenciam nos coeficientes tecnológicos. 
Tabela 2. Valores (em milhões de reais de 2009) estimados das reduções nos volumes de perdas pós-colheita de produtos agrícolas no Brasil em 2007, para os mesmos patamares de perdas de países de alta renda, em diferentes grupos de produtos, nas linhas, e etapas do processo de produção, nas colunas*

\begin{tabular}{lcccc}
\hline & $\begin{array}{c}\text { Manuseio pós-colheita } \\
\text { e armazenamento }\end{array}$ & $\begin{array}{c}\text { Processamento e } \\
\text { acondicionamento }\end{array}$ & Distribuição & $\begin{array}{c}\text { Total por grupo de } \\
\text { produto }\end{array}$ \\
\cline { 2 - 5 } & Perdas A1 & Perdas A2 & Perdas A3 & $(A 1+A 2+A 3)$ \\
\hline Cereais & - & 278 & 352 & 630 \\
Raízes e tubérculos & 510 & - & - & 510 \\
Oleaginosas/ leguminosas & 860 & 484 & 322 & 1.666 \\
Frutas e hortaliças & 1.113 & 1.219 & 127 & 2.459 \\
Carne & 294 & - & 550 & 844 \\
Peixes e frutos do mar & 67 & 6 & 2 & 75 \\
Leite & 760 & 100 & 939 & 1.799 \\
Ovos & - & - & 98 & 98 \\
\hline
\end{tabular}

* Conforme as fontes dos dados descritos na seção 3, os preços utilizados para calcular os valores da redução nas perdas, a partir dos volumes estimados, foram, em reais por tonelada: 392 para cereais; 330 para raízes e tubérculos; 689 para oleaginosas e leguminosas; 453 para frutas e vegetais; 3.371 para carnes; 1.380 para peixes e frutos do mar; 526 para leite e 2.630 para ovos.

Fonte: Resultados da pesquisa.

\section{Resultados e discussão}

Assim como descrito na seção anterior, os resultados foram apresentados em duas etapas. Primeiramente, a seção 4.1 apresenta os valores estimados decorrentes de redução nas perdas pós-colheita de produtos agrícolas no Brasil para os níveis observados em países de alta renda, segundo estimado pela FAO. A seguir, no item 4.2, são apresentadas as estimativas dos impactos sobre a economia brasileira resultantes de aumento dos serviços e seus impactos, dado o aumento no nível de produto disponível no País para diferentes etapas do processo pós-colheita.

\subsection{Redução das perdas de produtos agrícolas no Brasil}

Utilizando os dados e métodos descritos na seção 3.1, foram estimados os valores pelos quais as perdas em cada uma destas etapas poderia ser reduzida no Brasil, de maneira a atingir os patamares observados nos países mais ricos. Estes valores, em milhões de reais de 2009, são mostrados na Tabela 2. A soma dos valores descritos nesta tabela pode ser considerada como o valor do potencial de aumento das exportações agrícolas brasileiras, caso toda a redução das perdas fossem remetidas para o mercado internacional. Isto equivale a $\mathrm{R} \$ 8$ bilhões ao ano, a preços de 2009. A preços de $2012^{13}$, este valor corresponde a R \$ 9,8 bilhões que, segundo Brasil (2014), representa $25 \%$ do saldo positivo do Balanço Comercial do País em 2012 (US\$19,4 bilhões) ${ }^{14}$.

Além disto, conforme o método utilizado pela FAO (GUSTAVSSON et al., 2013) para estimar as perdas pós-colheita, todos os volumes estimados em cada etapa da cadeia consideraram, para o produto processado, o volume equivalente ao produto bruto que o originou. Assim, esta mesma consideração foi feita para os valores descritos na Tabela 2 , que estão em valores equivalentes do produto bruto. Como as perdas pós-colheita ocorrem também sobre o produto processado, o valor estimado total das perdas (R\$ 8 bilhões) é subestimado.

Entretanto, este valor não é o único impacto positivo sobre a economia brasileira decorrente de uma redução das perdas. A seguir, têm-se valores adicionais a este, que toda economia brasileira poderia auferir por esta redução das perdas, considerando o aumento na demanda por serviços que a produção recuperada demandaria e seus impactos.

13. Foi utilizado o Índice Geral de Preços - disponibilidade interna (IGP-DI), da Fundação Getúlio Vargas.

14. Foi considerada a taxa de câmbio de 2,04 em 2012. 


\subsection{Impactos na economia brasileira derivados da redução das perdas}

Como descrito na Tabela 2, a redução nas perdas de produtos agrícolas para o Brasil foi estimada para três etapas do processo produtivo. Entretanto, para responder à questão (iii) apresentada na introdução - Quais os choques sobre o mercado de bens e serviços da economia resultantes da redução nestas perdas? - estas informações foram utilizadas nas equações de (1) a (3). Desta maneira, obtivemos os valores dos choques na economia brasileira resultantes da redução das perdas em cada uma desta etapas, que foram: R\$ 3.456 milhões para o setor de "alimentos e bebidas" (Equação 1); R\$ 162 milhões para o setor de "transporte, armazenagem e correio" (Equação 2) e R\$ 1.386 milhão para o setor de "comércio" (Equação 3). Além disto, para que o impacto da produção agrícola não seja duplamente contabilizado, foram também considerados os seguintes choques negativos: -R $\$ 735$ milhões para o setor de "agricultura, silvicultura, exploração florestal" e -R 768 milhões para o setor de "pecuária e pesca".
Além dos choques de demanda, a redução no valor do multiplicador de impacto para os produtos agrícolas na matriz Leontief também foi realizada. Para isto, foi ponderada a redução percentual de cada grupo pelo valor da produção destes produtos, obtendo-se a média de $4,2 \%$. Este percentual foi aplicado como redução nos coeficientes $\mathrm{A}_{\mathrm{i}, \mathrm{i}}$ dos setores "agricultura, silvicultura, exploração florestal", "pecuária e pesca" e "alimentos e bebidas". Esta redução do multiplicador é importante para não superestimar os impactos multiplicadores do aumento de demanda identificados com a redução das perdas. A partir desta nova matriz de coeficientes técnicos diretos foi estimada a nova matriz inversa de Leontief, $(I-\bar{A})^{-1}$, utilizada para estimar os impactos descritos na Figura 2.

Os impactos diretos e seus efeitos multiplicadores na economia (impactos indiretos e de efeito renda) obtidos a partir destes choques, ilustrados na Figura 2, são apresentados separadamente para os choques de aumento de demanda: no processamento, no transporte e no comércio. Os impactos, inicialmente estimados a preços de 2009, foram transformados para preços de 2012

Figura 2. Valores estimados dos impactos difundidos sobre a economia brasileira resultantes da redução nas perdas pós-colheita de produtos agrícolas no Brasil

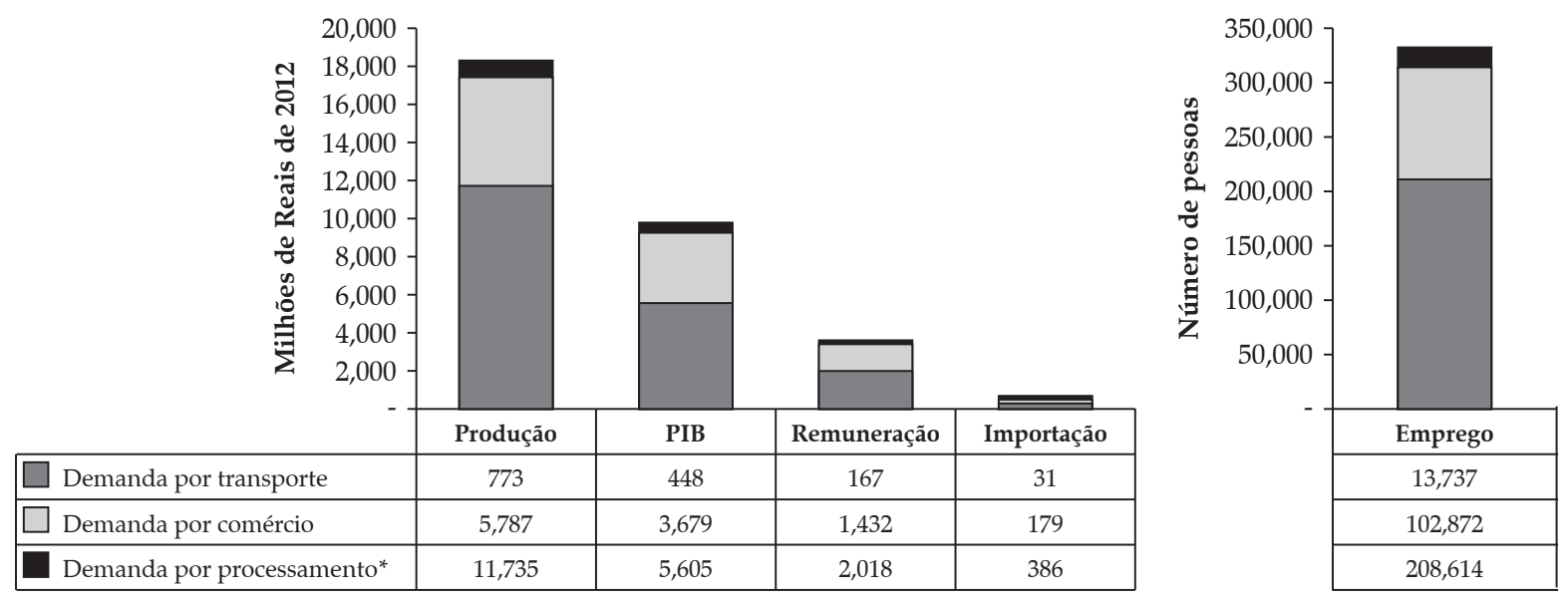

Nota: O impacto do aumento na demanda pelo processamento sobre os produtos que deixariam de ser perdidos na etapa anterior ao mesmo (pós-colheita e armazenamento), foi obtido somando os impactos positivos do aumento na demanda pelo valor equivalente de produto processado e os impactos negativos da redução na demanda pelos produtos agrícolas demandados deste aumento no processamento.

Fonte: Resultados da pesquisa. 
pelo deflator do PIB. Os valores apresentados nesta figura são a resposta para a questão (iv) exposta na introdução que é: quais os impactos econômicos para toda economia do País derivados destes choques?

Verifica-se que o aumento na demanda pelo processamento dos produtos agrícolas foi aquele que originou os maiores valores de choque, assim como de impactos na economia brasileira. Somente o aumento na demanda por este serviço causado pela redução nas perdas pós-colheita de produtos agrícolas no País poderia aumentar R\$ 11,7 bilhões em produção e R \$ 5,6 bilhões em PIB (preços de 2012). Derivado disto, um aumento de mais de 200 mil postos de trabalho e R\$ 2 bilhões em remuneração do trabalho seriam somados, ao ano, no País.

Os impactos econômicos derivados do aumento na demanda pelos serviços de transporte e comércio também são significativos. Apesar de terem originado os menores impactos, em termos absolutos, entre os três choques analisados, considerando o valor do choque aplicado (ou seja, em termos relativos), o aumento na demanda por transporte foi o choque que originou os maiores impactos multiplicadores na economia, causando um aumento total no valor da produção de R\$ 773 milhões. O aumento de mais de 13 mil postos de emprego originados por este choque é uma contribuição importante também para a economia do País.

No caso do aumento na demanda de comércio gerada pela redução nas perdas, o impacto multiplicador na economia poderia gerar aumento anual de R 5,7 bilhões em produção, R\$ 3,67 bilhões em PIB e R\$ 1,4 bilhão em remuneração (preços de 2012), além de gerar mais de 100 mil empregos.

Considerando a soma de todos os choques, verifica-se que os ganhos para a economia brasileira em termos de valor da produção de todos os produtos e serviços impactados por esta redução de perdas é quase o dobro do valor da redução das perdas estimadas na seção anterior (4.1), que foi de R\$ 9,8 bilhões a preços de 2012. Portanto, o impacto econômico total ocorre não apenas no valor da redução das perdas estimadas anteriormente, a qual já foi produzida pela economia, como também com o aumento na produção estimada nesta seção ( $\mathrm{R} \$ 18,2$ bilhões), derivada de aumento de demanda por serviços - o que equivale ainda a um aumento no valor do PIB de R\$ 9,7 bilhões, gerando mais de 320 mil empregos e R \$ 3,6 bilhões em remuneração. Esta ascensão econômica, entretanto, gera um aumento na demanda por importação no valor de R\$ 0,6 bilhão. Somada ao valor que o País poderia exportar pela redução nas perdas (R\$ 9,8 bilhões), isto representaria, ainda, um ganho no Balanço Comercial do País de R\$ 9,2 bilhões.

Adicionalmente à análise dos impactos da redução nas perdas por tipo de serviço não utilizado na economia brasileira (Figura 2), os impactos dos choques descritos foram também analisados de maneira separada para os grupos de produtos. Assim, a Figura 3 mostra o percentual dos impactos na economia brasileira atribuídos a cada um dos grupos de produtos considerados. Verifica-se nesta figura que as perdas pós-colheita para os grupos de frutas e hortaliças, raízes e tubérculos, bem como oleaginosas/ leguminosas, foram os que mais contribuíram para os impactos estimados na economia brasileira, respondendo por $70 \%$ dos impactos totais apresentados anteriormente. Já os choques referentes a estes três grupos representam 57\% dos choques totais analisados. Isto mostra a maior importância econômica na redução das perdas pós-colheita para estes produtos.

A contribuição descrita na Figura 3 mostra a média da participação de cada grupo dos produtos nas variáveis econômicas analisadas: produção, PIB, remuneração, importação e emprego. De maneira geral, esta participação foi muito semelhante entre as variáveis, o que justifica o valor médio apresentado. Entretanto, considerando os três grupos de produtos cujas reduções nas perdas mais impactaram a economia, verificou-se que: enquanto a participação das frutas e hortaliças no impacto sobre produção, importação e emprego foi de $24 \%$ dos impactos totais estimados, para PIB e remuneração esta participação 
Figura 3. Percentual dos impactos difundidos sobre a economia brasileira resultantes da redução nas perdas pós-colheita para cada um dos grupos de produtos agrícolas analisados (média da participação de cada grupo nas variáveis econômicas analisadas)

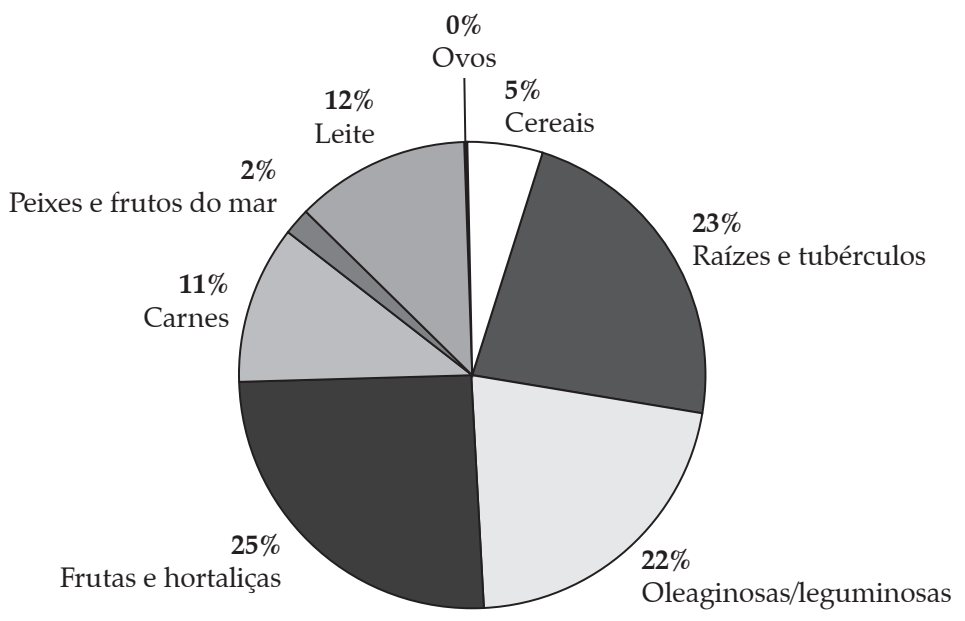

Fonte: Resultados da pesquisa.

aumenta para $27 \%$; para raízes e tubérculos, a participação no total do impacto em relação à média descrita na Figura 3, é maior sobre as importações brasileiras $(25 \%)$ e menor sobre o valor das remunerações $(21 \%)$, e para oleaginosas/leguminosas, enquanto foram observados $22 \%$ dos impactos sobre produção e emprego, sobre as demais variáveis esta participação foi de $21 \%$.

Com o objetivo de oferecer uma dimensão para estes impactos, o aumento anual no valor da produção estimado para a economia brasileira (R\$ 18,2 bilhões) corresponde a cerca de $80 \%$ do tamanho do valor da produção da cana-de-açúcar no País em 2009. Dado que este é um dos produtos agrícolas mais importantes no País, esta comparação oferece uma imagem da magnitude dos ganhos que a economia poderia auferir apenas pela redução de alguns poucos pontos percentuais nas perdas pós-colheita que são estimadas para alguns produtos agrícolas do País. Conforme pode ser observado na Tabela 1, a redução mais significativa ocorreu em $18 \%$ para o processamento e acondicionamento de frutas e hortaliças. Todas as demais reduções de perdas foram inferiores a $10 \%$. Assim, as reduções e impactos das mesmas estimados neste estudo podem ser ainda muito maiores pela melhoria nas reconhecidas deficiências na infraestrutura e no baixo nível de qualificação das pessoas que trabalham nas etapas pós-colheita destes produtos no País e que originam tais perdas.

\section{Conclusões}

A comercialização de produtos agroalimentares tem se constituído em desafio importante para a manutenção da competitividade brasileira. Dentre os aspectos que podem ser melhorados para aumentar a eficiência produtiva desse segmento, bem como de outros relacionados, sabe-se que a redução das perdas pós-colheita pode representar ganhos substanciais para a economia brasileira. De fato, estudo conduzido pela FAO mostrou que é na etapa pós-colheita que ocorrem as maiores perdas de produtos agrícolas. Isto foi mostrado e mensurado neste estudo. Observou-se que a magnitude dos ganhos potenciais são expressivos e podem ser empregados como parâmetros para uma análise de custo/benefício a ser utilizada na definição de políticas públicas para o investimento em infraestrutura logística, particularmente para o armazenamento, transporte e qualificação dos trabalhadores, dentre outros 
aspectos. Ou seja, este estudo pode ser utilizado como parâmetro em que gastos do governo de até cerca de R\$ 18 bilhões ao ano gerariam benefícios para a economia maiores do que o custo do investimento. Vale ressaltar que este valor é ainda subestimado, uma vez que não foram considerados outros impactos benéficos que poderiam ser gerados a partir destes investimentos e nem os impactos da sua implementação.

É importante atentar, no entanto, que os resultados obtidos devem-se, em grande parte, aos pressupostos assumidos para definir a base para a simulação dos impactos. Ou seja, utilizou-se como referência a diferença entre os percentuais de perdas verificadas na América Latina subtraída dos percentuais das perdas em países de alta e média renda. Embora essa seja uma definição válida para um ensaio da natureza proposta, face à inexistência de informações mais específicas ao caso brasileiro, também parece plausível considerar a possibilidade de que esses efeitos sejam ainda maiores, se a base de referência para reduções nas perdas de produtos agrícolas puder ser pautado em um levantamento mais específico às realidades edafoclimáticas e econômicas de cada país. Uma outra limitação dos resultados apresentados é que a matriz insumo-produto representa a tecnologia utilizada no país, e supomos reduzir os níveis de perdas pós-colheita sem alterar a matriz tecnológica.

\section{Referências}

BRASIL. Ministério do Desenvolvimento, Indústria e Comércio Exterior. Comércio Exterior. Estatísticas de
Comércio Exterior. Aliceweb. Disponível em: < http:// aliceweb.desenvolvimento.gov.br>. Acesso: 25 mar. 2014.

FAO. Food and Agriculture Organization of the United Nations. Statistics. Databases. FAOSTAT. Production. Disponível em: <http://faostat3.fao.org/faostatgateway/go/to/download/Q/*/E $>$. Acesso em: 6 mar. 2014a.

Food and Agriculture Organization of the United Nations. Statistics. Databases. Fisheries and aquaculture. Disponível em: < http://faostat3.fao.org/ faostat-gateway/go/to/download/Q/*/E $>$. Acesso em: 06 mar. 2014 b.

GUILHOTO, J. M. e SESSO FILHO, U. A. Estimação da matriz insumo-produto a partir de dados preliminares das Contas Nacionais. Economia Aplicada, v. 9, n. 1, abr./ jun. 2005.

GUSTAVSSON, J. et al. Global food losses and food waste: extent, causes and prevention. Food and agriculture organization of the United Nations - FAO. 2011.

. et al. The methodology of the FAO study: "Global food losses and food waste: extent, causes and prevention" - FAO, 2011. SIK report no 857, 2013.

IBGE. Instituto Brasileiro de Geografia e Estatística. Download. Estatísticas. Contas Nacionais. Disponível em: <http://downloads.ibge.gov.br/downloads_ estatisticas.htm >. Acesso em: 5 mar. 2014a.

Instituto Brasileiro de Geografia e Estatística.

Produção Agrícola Municipal. Disponível em: <http://www.ibge.gov.br/home/estatistica/economia/ pam/2012/>. Acesso em: 25 fev. 2014b.

Instituto Brasileiro de Geografia e Estatística.

Produção Pecuária Municipal. Disponível em: <http://www.ibge.gov.br/home/estatistica/economia/ ppm/2012>. Acesso em: 27 fev. 2014c.

MILLER, R. E. e BLAIR, P. D. Input-output analysis: foundations and extensions, ed. Cambridge: Cambridge University Press, 2009. 
Tabela 1A. Margens (percentuais em relação ao valor do produto a preços básicos) do processamento, do transporte e do comércio do produto bruto e do processado e aumento de valor do produto processado em relação ao bruto para os grupos de produtos agrícolas analisados (nas linhas)

\begin{tabular}{|c|c|c|c|c|c|c|}
\hline & \multirow{2}{*}{$\begin{array}{l}\text { Margem de } \\
\text { processamento } \\
\text { (a) }\end{array}$} & \multicolumn{2}{|c|}{ Margem transporte } & \multicolumn{2}{|c|}{ Margem comércio } & \multirow{2}{*}{$\begin{array}{c}\text { Aumento no } \\
\text { valor ao processar } \\
\text { (b) }\end{array}$} \\
\hline & & $\begin{array}{l}\text { Bruto } \\
\left(M t_{b}\right)\end{array}$ & $\begin{array}{l}\text { Processado } \\
\quad\left(M t_{p}\right)\end{array}$ & $\begin{array}{l}\text { Bruto } \\
\left(M c_{b}\right)\end{array}$ & $\begin{array}{l}\text { Processado } \\
\left(M c_{p}\right)\end{array}$ & \\
\hline Cereais & $62 \%$ & $1,1 \%$ & $2,6 \%$ & $10,9 \%$ & $14,7 \%$ & $337 \%$ \\
\hline Raízes e tubérculos & $32 \%$ & $2,6 \%$ & $2,5 \%$ & $3,3 \%$ & $6,7 \%$ & $536 \%$ \\
\hline Oleaginosas/leguminosas & $48 \%$ & $1,2 \%$ & $2,2 \%$ & $24,1 \%$ & $6,1 \%$ & $212 \%$ \\
\hline Frutas e hortaliças & $14 \%$ & $2,8 \%$ & $3,1 \%$ & $32,5 \%$ & $18,8 \%$ & $181 \%$ \\
\hline Carne & $73 \%$ & $0,04 \%$ & $0,8 \%$ & $4,5 \%$ & $23,8 \%$ & $253 \%$ \\
\hline Peixes e frutos do mar & $21 \%$ & $0,4 \%$ & $4,1 \%$ & $32,4 \%$ & $26,4 \%$ & $367 \%$ \\
\hline Leite & $71 \%$ & $0 \%$ & $2,1 \%$ & $6,3 \%$ & $29,7 \%$ & $153 \%$ \\
\hline Ovos & $11 \%$ & $3,8 \%$ & - & $15,3 \%$ & - & $0 \%$ \\
\hline
\end{tabular}

Nota: Para "cereais brutos" foi utilizada a média ponderada pelo valor da produção em 2009 dos produtos arroz em casca, milho em grão e trigo em grão e outros cereais. Para "cereais processados" foi utilizada a média ponderada pelo valor da produção em 2009 dos produtos arroz beneficiado e produtos derivados, farinha de trigo e derivados e óleos de milho, amidos e féculas vegetais e rações. Para "raízes e tubérculos brutos" foi utilizado o valor da produção em 2009 da mandioca. Para "raízes e tubérculos processados" foi utilizado o valor da produçao em 2009 da farinha de mandioca. Para "oleaginosas e leguminosas brutos" foi utilizada a média ponderada pelo valor da produção em 2009 dos produtos soja em grão e algodão herbáceo. Para "oleaginosas e leguminosas processados" foi utilizada a média ponderada pelo valor da produção em 2009 dos produtos óleo de soja em bruto e tortas, bagaços e farelo de soja; outros óleos e gordura vegetal e animal exclusive milho; óleo de soja refinado. Para "frutas e hortaliças brutos" foi utilizada a média ponderada pelo valor da produção em 2009 dos produtos outros produtos e serviços da lavoura e frutas cítricas. Para "frutas e hortaliças processados" foi utilizado o valor da produção de conservas de frutas, legumes e outros vegetais. Para "peixes e frutos do mar bruto" foi utilizado o valor da produção em 2009 do produto "pesca e aquicultura" e para "peixes e frutos do mar processado", o valor da produção do produto "pescado industrializado". Para "carne bruta" foi utilizada a média ponderada pelo valor da produção em 2009 dos produtos bovinos e outros animais vivos; suínos vivos e aves vivas. Para "carne processada" foi utilizada a média ponderada pelo valor da produção em 2009 dos produtos abate e preparação de produtos de carne; carne de suíno fresca, refrigerada ou congelada; carne de aves fresca, refrigerada ou congelada. Para "leite bruto" foi utilizado o valor da produção em 2009 do produto leite de vaca e de outros animais. Para "leite processado" foi utilizado o valor da produção em 2009 do produto leite resfriado, esterilizado e pasteurizado. Para "ovos" apenas considerou-se o valor do produto bruto, referente ao produto "ovos de galinha e de outras aves". Por este motivo não estão descritas margens para o produto processado em ovos.

Fonte: Calculado pelos autores a partir dos dados das Contas Nacionais do Brasil de 2009 (IBGE, 2014a). 